\title{
Primary biliary cirrhosis and hemolytic anemia confusing serum bilirubin levels
}

\author{
M Brackstone MSc, Cameron N Ghent MD
}

\begin{abstract}
M Brackstone, CN Ghent. Primary biliary cirrhosis and hemolytic anemia confusing serum bilirubin levels. Can J Gastroenterol 2000;14(5):445-447. Hemolysis is observed in more than $50 \%$ of patients with cirrhosis. However, there has been little documention of the association of primary biliary cirrhosis with autoimmune hemolytic anemia. Two cases, found within a single practice, of primary biliary cirrhosis coexisting with autoimmune hemolysis and a third case coexisting with hereditary spherocytosis are presented. Anemia in such patients is commonly attributed to chronic disease, and hyperbilirubinemia is attributed to primary biliary cirrhosis. These patients were considered for liver transplantation until the diagnosis of a comorbid hemolytic process was established. This association may be more prevalent than previously recognized. A diagnosis of comorbid hemolysis must always be considered in context with anemia and serum bilirubin levels that rise out of proportion to the severity of the primary biliary cirrhosis.
\end{abstract}

Key Words: Hemolytic anemia; Primary biliary cirrhosis; Serum bilirubin levels

\section{Cirrhose biliaire primitive, anémie hémolytique et taux de bilirubine sérique}

RÉSUMÉ : Plus de $50 \%$ des patients souffrant de cirrhose présentent aussi de l'hémolyse. Cependant, il existe peu de documentation sur la concomitance de la cirrhose biliaire primitive et de l'anémie hémolytique auto-immune. Voici deux cas, observés dans un même cabinet, de cirrhose biliaire primitive associée à une hémolyse auto-immune et un troisième cas de même maladie associée à une microsphérocytose héréditaire. L'anémie est généralement attribuée à la maladie chronique, et l'hyperbilirubinémie, à la cirrhose biliaire primitive. Les patients dont le cas est exposé ci-dessous étaient candidats à une transplantation du foie jusqu'à ce qu'un diagnostic de processus hémolytique comorbide fût posé. Ce type d'association est peut-être plus fréquent qu'on le pense. Il faut donc toujours envisager la possibilité d'hémolyse comorbide dans les cas où l'anémie et les taux de bilirubine sont hors de proportion par rapport à la gravité de la cirrhose biliaire primitive.
$\mathrm{P}$ rimary biliary cirrhosis $(\mathrm{PBC})$ is a chronic cholestatic disease, characterized by progressive fibrosis with septal and interlobular duct destruction (1). PBC is most common in women and is often associated with other autoimmune diseases such as scleroderma, rheumatoid arthritis, thyroiditis and polymyalgia rheumatica, and consequently is considered a prototypical autoimmune disease (1).

Hemolysis is observed in more than half of all patients with cirrhosis, regardless of their disease etiology (2). However, little literature is available regarding any association between PBC and autoimmune hemolytic anemia, or other severe hemolytic states (3).

Two patients seen within a single practice, a case of hereditary spherocytosis coexisting with $\mathrm{PBC}$ and a literature review to suggest that autoimmune hemolytic anemia may be considered another autoimmune disease associated with PBC are presented. The relevance of this association lies in the effect of the comorbid hemolysis that raises serum bilirubin levels, such that missing the hemolysis diagnosis may confuse the physician into thinking that the $\mathrm{PBC}$ is more se-

Liver Diseases and Transplantation, University of Western Ontario, London, Ontario

Correspondence and reprints: Dr CN Ghent, Liver Diseases and Transplantation, 408-140 Oxford St E, London, Ontario, N6A 5R9.

Telephone 519-642-3232, fax 519-642-2545, email cghent@julian.uwo.ca

Received for publication May 30, 1998. Accepted December 29, 1998 


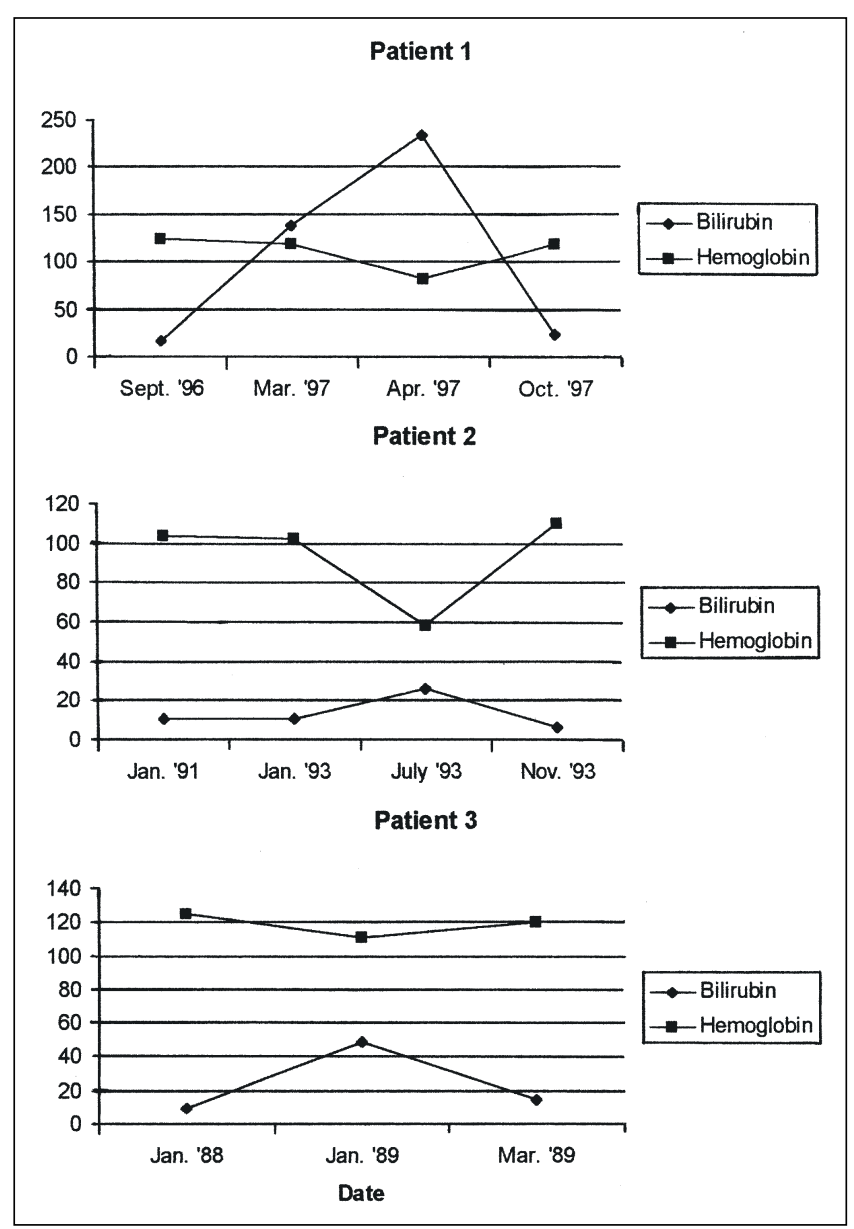

Figure 1) Serum bilirubin ( $\mu \mathrm{mol} / \mathrm{L})$ and hemoglobin $\left(10^{-9} / \mathrm{L}\right)$ levels before, during and after treatment for hemolytic anemia in patients with primary biliary cirrhosis

vere than it actually is. The case of hereditary spherocytosis is presented to illustrate further this problem.

\section{CASE PRESENTATIONS}

Patient 1: A 49-year-old woman presented in 1988 with general fatigue and pruritus. The diagnosis of $\mathrm{PBC}$ was confirmed by a positive test for mitochondrial antibodies and a liver biopsy that showed stage IV PBC. She was treated with cholestyramine and ursodiol. Her disease was considered to be stable (alanine aminotransferase $168 \mu \mathrm{mol} / \mathrm{L}$, aspartate aminotransferse $157 \mu \mathrm{mol} / \mathrm{L}$, alkaline phosphatase $551 \mu \mathrm{mol} / \mathrm{L}$ and bilirubin $17 \mu \mathrm{mol} / \mathrm{L}$ ). Her course was complicated by hypothyroidism and osteodystrophy. In February of 1997, her jaundice had worsened (bilirubin $235 \mu \mathrm{mol} / \mathrm{L}$ ) without any appreciable change in liver enzyme levels. Abdominal ultrasound showed no dilation of the bile ducts. She complained of dark urine and pale stools, and her jaundice was considered to reflect her worsened cholestasis. Her physical examination confirmed palpable splenomegaly, without lymphadenopathy or palpable hepatomegaly. However, her lactic dehydrogenase (LDH) level was greater than 1000 and her hemoglobin level fell to $82 \mathrm{~g} / \mathrm{L}$ with a mean corpuscular volume of $113 \mathrm{fL}$ and a reticulocyte count of 693 .
A direct antiglobulin test was positive for immunoglobulin G. It was determined that she had cold type autoimmune hemolytic anemia. Because of concerns about the predictable negative effects of steroids on her osteodystrophy, liver transplantation for PBC combined with splenectomy for the hemolytic anemia was considered. However, a trial of prednisone $50 \mathrm{mg} /$ day was elected, with ursodiol $1 \mathrm{~g} /$ day, alendronate $10 \mathrm{mg} /$ day, thryroxine $100 \mu \mathrm{g} /$ day, folic acid $10 \mathrm{mg} /$ day and cholestyramine $4 \mathrm{~g}$ bid to maintain therapy. Her serum bilirubin level promptly fell from 235 to $45 \mu \mathrm{mol} / \mathrm{L}$, and her hemoglobin level rose from $82 \mathrm{~g} / \mathrm{L}$ to $119 \mathrm{~g} / \mathrm{L}$ (Figure 1). After six months of prednisone treatment, steroids were withdrawn and she maintained pretreatment levels of hemoglobin and bilirubin for the subsequent year.

Patient 2: A 66-year-old woman presented in 1991 with a $13.6 \mathrm{~kg}$ weight loss over 12 months, with worsening pruritus and fatigue over six months. Her history included osteoarthritis and a cholecystectomy, but no risk factors for chronic liver disease and no known autoimmune diseases. She tested positive for mitochondrial antibodies, and her immunoglobulin M level was $9.5 \mathrm{~g} / \mathrm{L}$. She was shown to have stage III $\mathrm{PBC}$ on liver biopsy and was treated with cholestyramine and ursodiol. In 1993, she developed dyspnea and pallor, and was found to be anemic with a hemoglobin level of $58 \mathrm{~g} / \mathrm{L}$. Her bilirubin level rose from 7 to $26 \mu \mathrm{mol} / \mathrm{L}$ (Figure 1). A direct antiglobulin test was positive for warm type hemolytic anemia. Treatment with prednisone $20 \mathrm{mg} /$ day was elected; azathioprine $100 \mathrm{mg} /$ day was started after she responded to prednisone. The prednisone dose was tapered and discontinued after one year. She remained on azathioprine $100 \mathrm{mg} /$ day with normal blood counts in the subsequent three years of follow-up.

Patient 3: A 35-year-old woman was referred for liver transplantation assessment for PBC of 30 months. She was obviously icteric and had a palpable spleen $6 \mathrm{~cm}$ below the costal margin, without palpable hepatomegaly or other signs of portal hypertension. Upper gastrointestinal endoscopy showed no signs of portal hypertension. Review of a previous liver biopsy showed stage $1 \mathrm{PBC}$ and normal liver function (albumin $41 \mathrm{~g} / \mathrm{L}$, international normalized ratio 1.0). Alkaline phosphatase was $161 \mu \mathrm{mol} / \mathrm{L}$, bilirubin $49 \mu \mathrm{mol} / \mathrm{L}$ and antimitochondrial antibody was positive at one to 64 dilution. Her serum hemoglobin level was $111 \mathrm{~g} / \mathrm{L}$, and review of a blood film showed microspherocytes. Further investigation of her family history confirmed splenomegaly, anemia and spherocytosis in the patient's father. Splenectomy was performed to treat her hereditary spherocytosis. The liver appeared grossly normal to the surgeon, and her serum bilirubin level fell to $15 \mu \mathrm{mol} / \mathrm{L}$ postoperatively (Figure 1).

\section{DISCUSSION}

An association between $\mathrm{PBC}$ and various other autoimmune conditions has been described clearly (1-5). In addition, the presence of reduced red blood cell survival with all types of cirrhosis, including PBC, has been well documented (1). The mechanism for this is not clear and may involve intracorpuscular or extracorpuscular mechanisms (1). Because of 
the common association between $\mathrm{PBC}$ and other autoimmune conditions, it is logical to consider that autoimmune hemolysis may be another condition seen in association with $\mathrm{PBC}$, and creates more potential for confusion in recognizing and characterizing anemia, and/or hyperbilirubinemia in this setting.

This case series presents two patients with autoimmune hemolysis, and one with hereditary spherocytosis that demonstrate the diagnostic problems arising when $\mathrm{PBC}$ and hemolysis coexist. One patient had cold type and another had warm type autoantibodies to red blood cells; both patients experienced autoimmune hemolysis to steroid treatment with resolution of jaundice and anemia. It is surprising that both patients were able to have steroid treatment withdrawn without a relapse of hemolysis. The patient with hereditary autoimmune hemolytic anemia illustrates that similar confusion about serum bilirubin elevations can arise with other causes of hemolysis in patients with PBC, and that hyperbilirubinemia resolves with appropriate treatment of the hematological disorder. Gilbert's syndrome may likewise produce a confusing, disproportionate elevation of serum bilirubin levels in early $\mathrm{PBC}$ but was not present in any of our cases. It should not be associated with anemia and can be readily diagnosed by using bilirubin fractionation and reticulocyte counts.

Surprisingly, there have been few case reports of autoimmune hemolytic anemia associated with $\operatorname{PBC}(2,6-8)$. The first report of warm type hemolysis was in a study of red blood cell survival (2). Subsequent case reports (6-8) documented an association between autoimmune hemolytic anemia and PBC. One case report documented autoimmune hemolytic anemia and autoimmune myocarditis in a patient with PBC (9). The remaining literature reports that the attempts made to demonstrate an association between PBC and autoimmune hemolysis were complicated by histories of use of medications that may induce autoimmune hemolytic anemia $(8,10-12)$. This raises concerns that the association may be with the medication rather than with the disease. Two of the patients discussed above illustrate that autoimmune hemolysis is possibly secondary to rifampin for treatment of tuberculosis $(8,11)$. The third patient report discussed autoimmune hemolytic anemia and tiopronin, although hemolysis began before the use of tiopronin (12). Only one case of cold type autoimmune hemolytic anemia and PBC appeared to be without other autoimmune comorbid conditions or drug induction (7). This patient presented with hemolytic anemia four years after $\mathrm{PBC}$ was diagnosed. This patient was enrolled in a study to determine the effect of plasma exchange on hemolytic anemia, but died shortly after the study was initiated.

The present cases demonstrate that the onset of autoimmune hemolytic anemia may occur after the diagnosis of PBC. This raises some clinical dilemmas for following the clinical course of PBC with serum bilirubin levels. Unless the possibility of a secondary diagnosis of some form of hemolysis is considered, the PBC may be considered to be solely responsible for the elevated serum bilirubin level. It is then easy to conclude erroneously that the PBC is advanced and to recommend an inappropriate therapy, as shown in the patient with autoimmune hemolytic anemia. Serum bilirubin levels have long been known to be important in assessing the prognosis of PBC $(13,14)$, and confounding hemolysis may lead to erroneous conclusions about the severity of the disease. Therefore, we recommend that patients with PBC whose serum bilirubin levels are disproportionate to the apparent stage of their disease or whose serum bilirubin levels rise suddenly undergo screening for associated hemolysis.

\section{CONCLUSIONS}

The intent of this report is to demonstrate that the association between $\mathrm{PBC}$ and autoimmune hemolytic anemia is real and must always be considered, especially in the setting of anemia and serum bilirubin levels that rise disproportionately to the patient's stage of PBC. The literature review documents a number of such cases described in isolation, but the frequency of the association may be higher than previously appreciated.

\section{REFERENCES}

1. Culp KS, Fleming CR, Duffy J, et al. Autoimmune associations in primary biliary cirrhosis. Mayo Clin Proc 1982;57:365-70.

2. Hume R, Williamson JM, Whitelaw JW. Red cell survival in biliary cirrhosis. J Clin Pathol 1970;23:397.

3. Mahl MA, von Schonfeld J, Uppenkamp M, Breuer N. Hemolytic anemia as cause of a marked bilirubin increase in primary biliary cirrhosis. Dtsch Med Wochenschr 1996;121:1226-8.

4. Besancon F, Touraine R, Bilski-Pasquier G. Reynold's syndrome associated with primary biliary cirrhosis, telangiectasia, scleroderma and, in one case, hemolytic anemia and Gougerot-Sjogren syndrome. Ann Med Interne (Paris) 1974;125:663-5.

5. Dauphinee JA, Sinclair JC. Primary biliary cirrhosis. Can Med Assoc J 1949;61:1.

6. Jaccard Y, DiStefano R, Breaud P, Delacretaz F, Pontolliet A. Value of anti-Ro anitbodies in two cases of Sjorgren's disease with multisystem involvement. Schweiz Med Wochenschr 1989;119:84-7.

7. Orlin JB, Berkman EM, Matloff DS, Kaplan MM. Primary biliary cirrhosis and cold autoimmune hemolytic anemia: Effects of partial plasma exchange. Gastroenterology 1980;78:576-8.

8. Yoshida FM, Nantel SH, Owen DA, et al. Case report: A patient with primary biliary cirrhosis and autoimmune hemolytic anemia. J Gastroenterol Hepatol 1996;11:439-42.

9. Wolf HW. Autoimmune myocarditis, hemolytic anemia and primary biliary cirrhosis. Dtsche Med Wochenschr 1982;107:77. (Lett)

10. Kazuta Y, Watanabe N, Sagawa K, et al. A case of autoimmune hemolytic anemia induced by IFN-beta therapy for type-C chronic hepatitis. Fukushima J Med Sci 1995;41:43-9.

11. Pereira A, Sanz C, Castillo R. Immune hemolytic anemia and renal failure associated with rifampin-dependent antibodies with anti-T specificity. Ann Hematol 1991;63:56-8.

12. Shichiri M, Koyama W, Tozuka S, Sakamoto S, Kanayama M. Primary biliary cirrhosis - A patient with adverse reactions to Tiopronin and autoimmune hemolytic anemia with reticulocytopenia. Arch Intern Med 1984;144:89-91.

13. Shapiro JM, Smith H, Schaffner F. Serum bilirubin, a prognostic factor in primary biliary cirrhosis. Gut 1979;20:137.

14. Pasha TM, Dickson ER. Survival algorithms and outcome analysis in primary biliary cirrhosis. Semin Liver Dis 1997;17:147-58. 


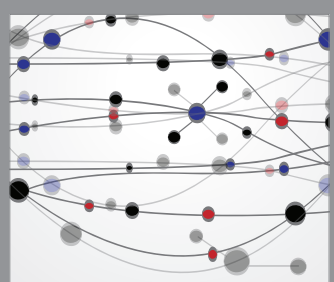

The Scientific World Journal
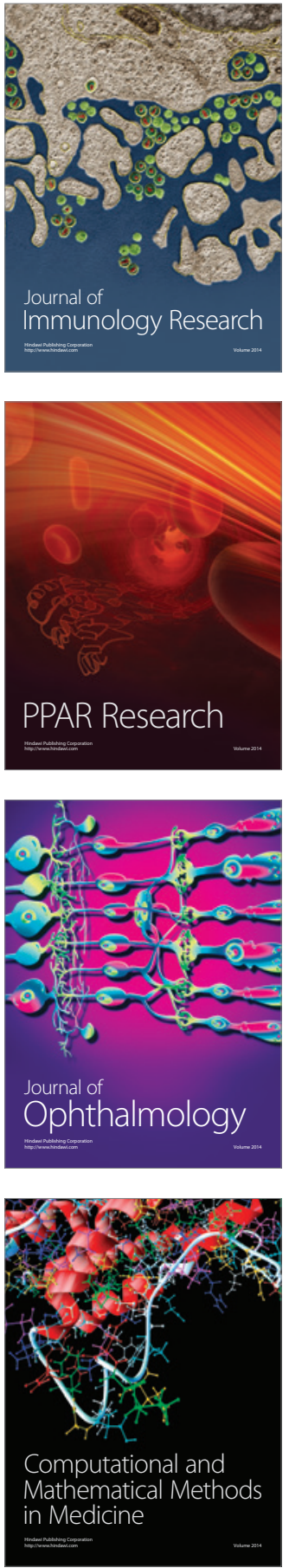

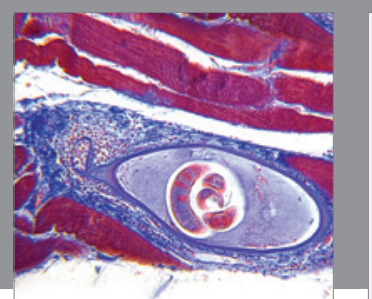

Gastroenterology Research and Practice

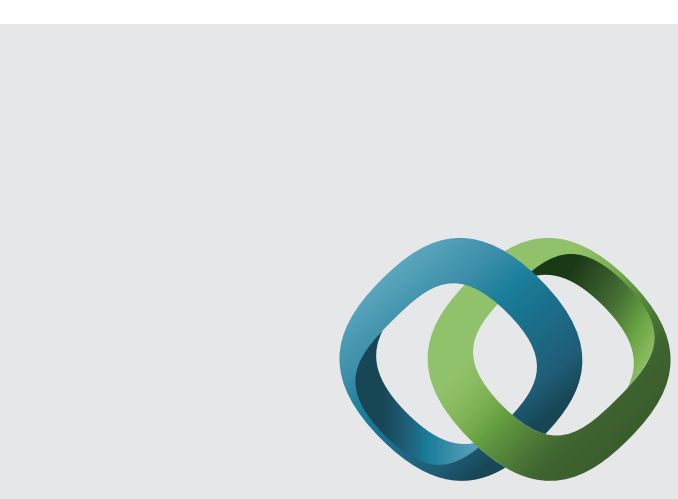

\section{Hindawi}

Submit your manuscripts at

http://www.hindawi.com
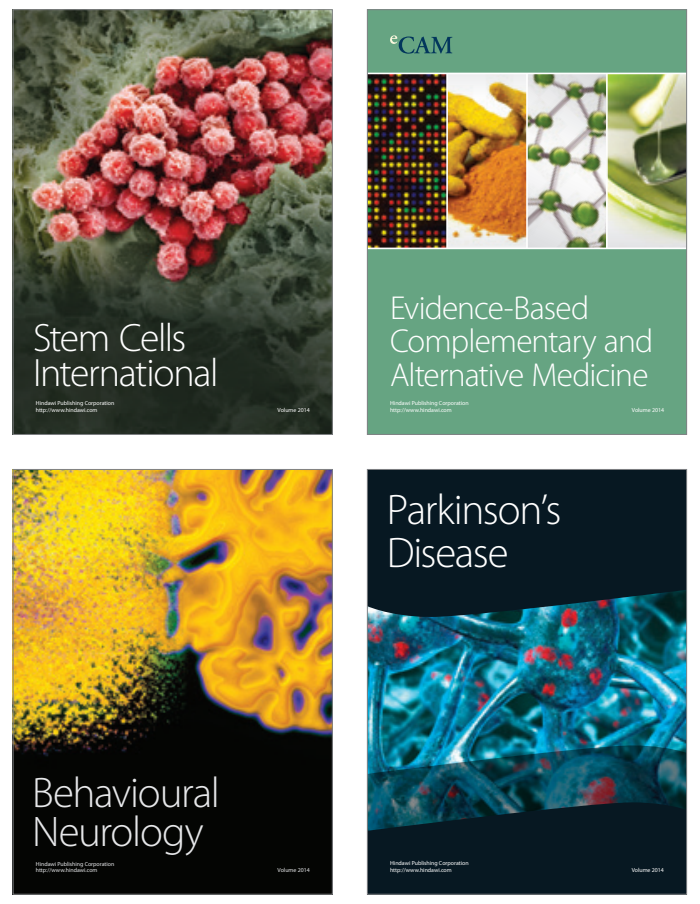
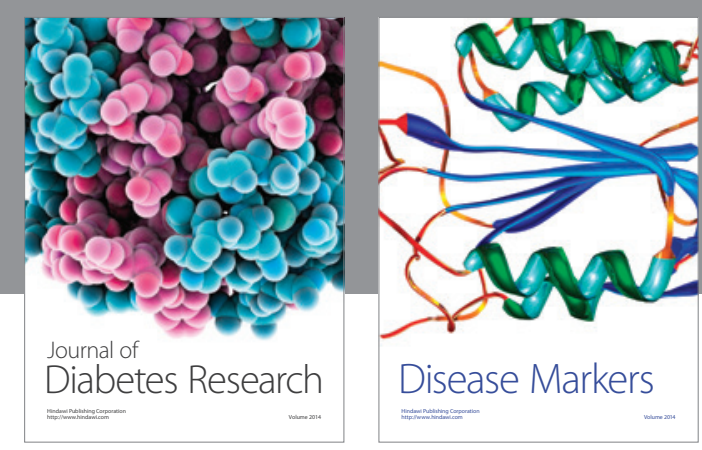

Disease Markers
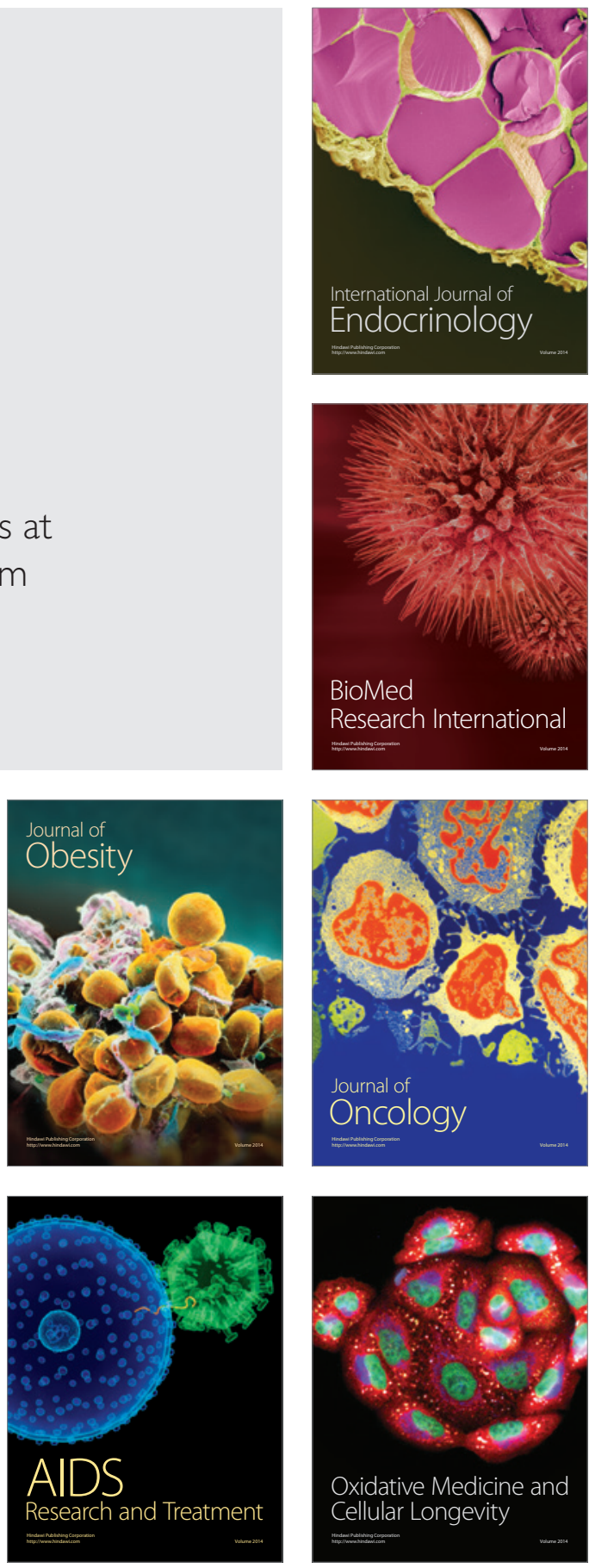